\title{
BLOOD OXYGEN STUDIES IN PREMATURE INFANTS
}

\author{
BY \\ PATRICIA M. RUSSELL and F. P. HUDSON \\ From Walton Hospital, Liverpool, and the Department of Child Health, University of Liverpool
}

(RECEIVED FOR PUBLICATION APRIL 4, 1957)

Certain features peculiar to premature babies appear to justify the routine use of oxygen. Cyanotic attacks are frequent, an irregular respiratory rhythm is common, and in the smaller infants the pulmonary alveoli are incompletely developed and present a thicker barrier than normal between the alveolar air and the blood stream. Graham, Reardon, Wilson, Tsao and Baumann (1950) and Wilson, Long and Howard (1942) have shown that the respirations of a premature baby will become regular when oxygen is administered. Malm (1953) observed an increased uptake of oxygen by small premature babies who were placed in an oxygen-enriched atmosphere and suggested that their previous oxygen consumption was inadequate. The work of Smith and Kaplan (1942), Graham et al. (1950) and Taylor (1954) has shown that the blood oxygen saturation in smaller premature infants is lower and subject to wider variations than in full-term infants. It should not, however, be assumed that these features are necessarily harmful to the baby who is born before term, and indeed, they may not require correction.

The work reported in this paper was undertaken in 1954 to determine the oxygen saturation of blood obtained from premature babies by heel stab.

\section{Method}

Forty premature babies in the Premature Baby Unit of Walton Hospital, Liverpool, were studied for varying periods from the time of birth to the age of 3 months. Haemoglobin and blood oxygen estimations were made on cutaneous blood obtained by heel stab. It has been shown that the oxygen content of 'cutaneous' blood is almost identical with that of arterial blood provided that there is vasodilatation and a rapid blood flow (Hultgren and Hackett, 1950; Lundsgaard and Möller, 1922). No special effort was made to warm the limb before the sample was taken but all infants were lying quietly in a cot or incubator with a surrounding temperature approaching $90^{\circ} \mathrm{F}$. No infant was crying before the heel stab was made but they invariably did so immediately afterwards. After cleansing with ether the heel was stabbed with a sharp Hagedorn needle and the first drop of blood was discarded. The haemoglobin pipette was then filled and the heel wiped dry. Another pipette was then placed over the incision so that there was no. contact between the air and the blood that was to be used for oxygen estimation. The oxygen content of this sample was determined immediately.*

The haemoglobin was estimated by the Medical $\stackrel{\circ}{\circ}$ Research Council Grey wedge photometer, the accuracy of the instrument in use being checked at intervals. The oxygen content was estimated by the microgasometric of method of Roughton and Scholander (1943). This $\omega$ method has certain advantages over the standard Van $\underset{N}{\mathbb{N}}$ Slyke procedure in that it is simple and rapid and requires 0 only a very small quantity of blood. It is accurate to about $0 \cdot 15$ volumes $\%$.

The oxygen capacity of the blood was obtained by calculation from the haemoglobin content, assuming that $\overrightarrow{0}$ $1 \mathrm{~g}$. of haemoglobin combines with $1.34 \mathrm{ml}$. of oxygen (Hüfner, 1894). The amount of oxygen in simple solution was subtracted from the total oxygen conteRt as obtained from the Roughton-Scholander estimation in order to obtain the amount of oxygen combined wi the haemoglobin, using the formula:

Dissolved oxygen (vol.) $=\mathrm{pO}_{2} \times \mathrm{O}_{2}$ (where $\mathrm{pO}_{2}=-$ partial pressure of oxygen in lungs, and $\mathrm{O}_{2}=$ Bunsen solubility coefficient.)

To determine the effect on the blood oxygen concentration of raising the oxygen content of the inspired air, infants were placed under a 'perspex' hood in an atmosphere of 55 to $60 \%$ oxygen for one hour, blood samples being collected before and at the end of this period. The oxygen content of the air-gas mixture was determinedo by a simple pyrogallol apparatus.

\section{Results}

Haemoglobin. Fig. 1 demonstrates the marked fall in haemoglobin during the first eight weeks of life. During the first week of life the mean haemoglobin level was almost $20 \mathrm{~g}$. per $100 \mathrm{ml}$., by the endo of the fourth week it was only $13 \mathrm{~g}$. per $100 \mathrm{ml}$. and by the eighth week only $9 \cdot 8 \mathrm{~g}$. per $100 \mathrm{ml}$.

Oxygen Content. The fall in oxygen contentr during the first eight weeks of life is indicated in Fig. 2. During the first week of life the mean blood

* All estimations reported in this paper were made by P.M.R. 
oxygen content was 23 vol. \% with individual readings varying between 14.9 and 30.7 vol. $\%$. By the end of the fourth week the average oxygen content had fallen to $16 \mathrm{vol}$. $\%$ with individual readings varying between $9 \cdot 2$ and 20.0 vol. \%. By the eighth week there had been a further fall to 10.0 vol. $\%$ with a range from 7.8 to $12.6 \mathrm{vol}$. \%. (The oxygen content of blood with a haemoglobin content of $14.8 \mathrm{~g}$. per $100 \mathrm{ml}$, which is $100 \%$ saturated with oxygen, is $19.8 \mathrm{vol} . \%$.)

Percentage Oxygen Saturation. The fall of blood oxygen content during the first eight weeks of life parallels the fall in haemoglobin which occurs during

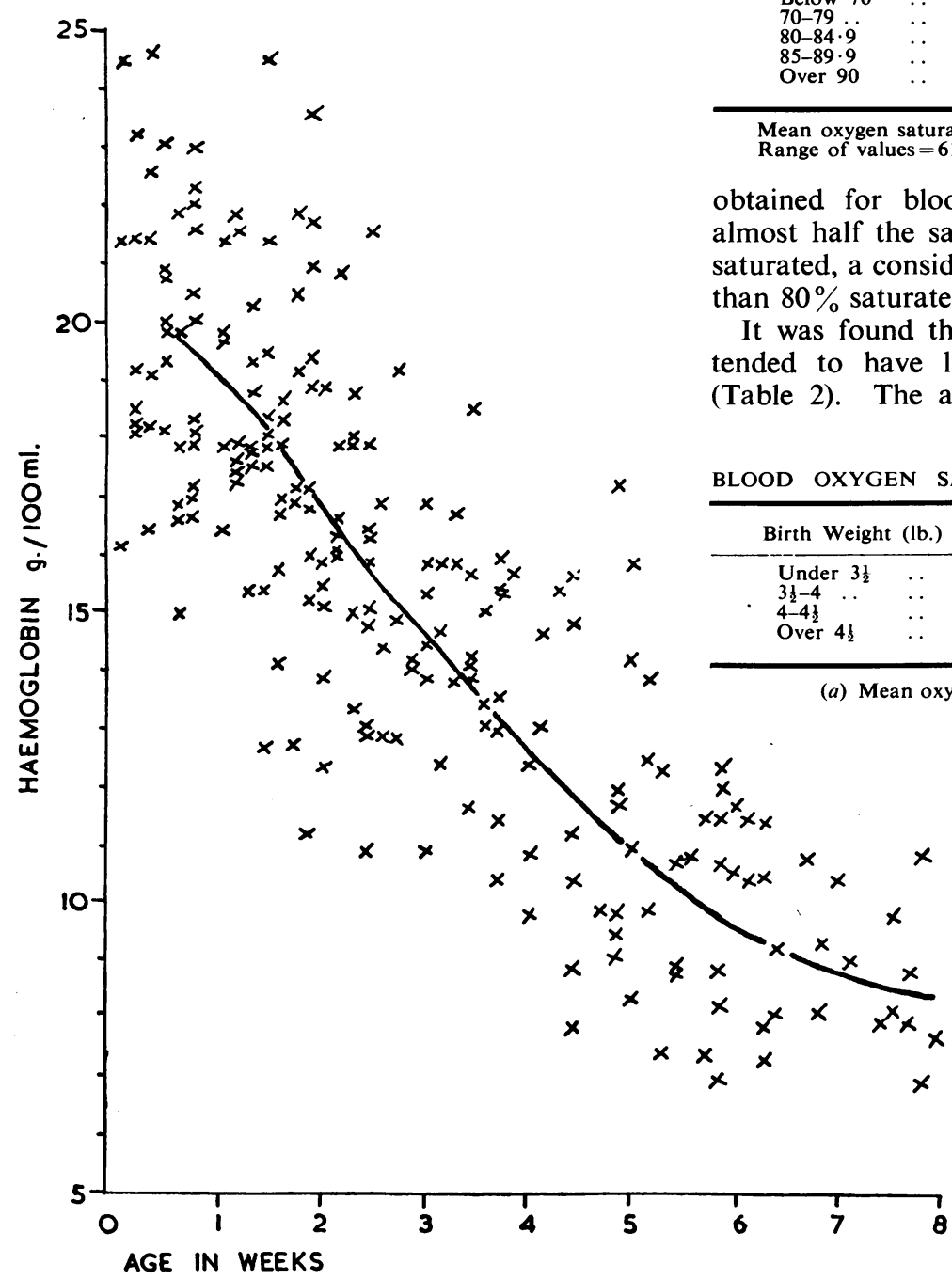

FIG. 1.-Individual haemoglobin values and average curve. the same period. The percentage oxygen saturation of the blood, therefore, remains about the same.

Fig. 3 is a scattergram showing all the values obtained for blood oxygen saturation charted according to age. The mean blood oxygen saturation of the 238 determinations on 40 infants was $88.8 \%$ (S.D. $8 \cdot 8$ ) with a range of values from $61 \cdot 5 \%$ to $102 \cdot 5 \%$.

Table 1 demonstrates the distribution of results TABLE 1

PERCENTAGE OXYGEN SATURATION OF CUTANEOUS BLOOD IN 40 INFANTS

\begin{tabular}{|c|c|c|c|c|}
\hline \multicolumn{3}{|c|}{ Oxygen Saturation $(\%)$} & No. of Readings & Percentage \\
\hline $\begin{array}{l}\text { Below } 70 \\
70-79.9 \\
80-84 \cdot 9 \\
85-89 \cdot 9 \\
\text { Over } 90\end{array}$ & $\begin{array}{l}\cdots \\
\cdots \\
\cdots \\
\cdots\end{array}$ & $\begin{array}{l}\cdots \\
\cdots \\
\cdots \\
\cdots\end{array}$ & $\begin{array}{r}6 \\
33 \\
31 \\
50 \\
118\end{array}$ & $\begin{array}{l}\left.\begin{array}{r}2 \cdot 5 \\
13 \cdot 9\end{array}\right\} \\
13 \cdot 0 \\
21 \cdot 0 \\
49 \cdot 6\end{array}$ \\
\hline
\end{tabular}

Mean oxygen saturation of blood $=88 \cdot 8 \%$ (S.D. $8 \cdot 8$ ).

obtained for blood oxygen saturation. Though almost half the samples examined were over $90 \%$ saturated, a considerable number $(16.4 \%)$ were less than $80 \%$ saturated with oxygen.

It was found that infants of lower birth weight tended to have lower blood oxygen saturations Table 2). The average blood oxygen saturation

TABLE 2

TURATION AND BIRTH WEIGHT

Mean Saturation (\%) $\quad$ S.D.

\begin{tabular}{r|r}
86.0 & 9.5 \\
89.9 & 8.5 \\
88.5 & 8.5 \\
90.1 & 8.5
\end{tabular}

$90 \cdot 1$

$8 \cdot 5$

$7 \cdot 5$
$8 \cdot 5$
$8 \cdot 5$
$8 \cdot 5$

(a) Mean oxygen saturation and birth weight.

of infants weighing less than $3 \frac{1}{2} \mathrm{lb} .(1.6 \mathrm{~kg}$.) at birth was $86.0 \%$ (S.D. 9.5) compared with $90 \cdot 1 \%$ for infants weighing over $4 \frac{1}{2} \mathrm{lb}$. $(2 \mathrm{~kg}$.) at birth.

Fig. 4 and Table 3 compare the values of blood oxygen saturations of premature and full-time infants. The mean percentage oxygen saturation of premature infants $(88.8 \%)$ was lower than that of the fulltime infants $(93.0 \%)$, the range of values was greater, and more low figures were recorded. Similar investi- 
gations on 13 adults gave a mean blood oxygen saturation of $96.4 \%$.

The Results of Administration of Oxygen. The administration of oxygen for short periods to our

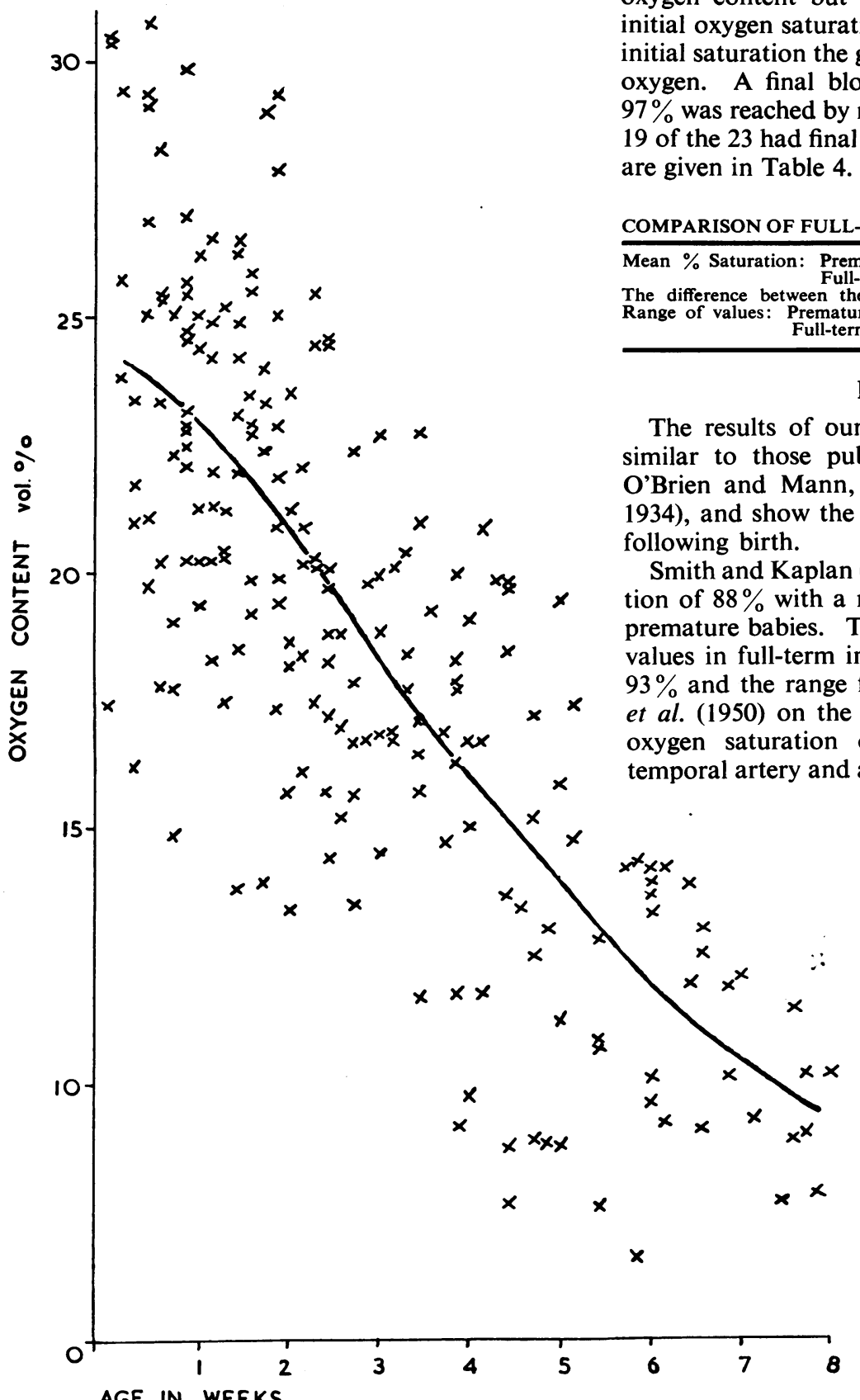

AGE IN WEEKS

FIG. 2.-Individual blood oxygen values and average curve. premature infants resulted in an increase in the oxygen content and saturation of the blood on 21 of the 23 occasions on which it was given. The extent of the increase was not related to the initial oxygen content but was in general related to the initial oxygen saturation of the blood, the lower the A the greater the increase after giving final blood oxygen saturation of over was reached by more than half the infants, and 19 of the 23 had final saturations over $90 \%$. Details TABLE 3 COMPARISON OF FULL-TERM AND PREMATURE INFANTS Premature: $88 \cdot 8 \%$ (S.D. 8:8).
Full-term: $93 \cdot 0 \%$ (S.D. $6 \cdot 47$ ).

The difference between the two groups is significant $(t=3.93)$, remature: 61.5 to $102.5 \%$

\section{Discussion}

The results of our haemoglobin estimations are similar to those published by others (Arthurton, O'Brien and Mann, 1954; Merrit and Davidson, 1934), and show the expected fall in the few weeks flowing birth.

Smith and Kaplan (1942) found an average saturaet al. (1950) on the other hand found the average oxygen saturation of blood obtained from the emporal artery and as determined by the Van Slyke method to be $93 \%$. In their investigation the younger premature infants (1-14 days) gave essentially the same results as the older group (14-65 days). Jonxis (1953), using a photoelectric apparatus, found that 'in nearly all examined mature and premature infants the oxygen saturation is on the same level as that of adults, viz., $97 \%$, but he also states that greater variations occur in premature infants.

Graham et al. (1950) report that on placing premature infants in an atmosphere of 70 to $79 \%$ oxygen the average arterial saturation rose from $93 \%$ to $100 \%$, and in an atmosphere of $80 \%$ to 
TABLE 4

EFFECT OF OXYGEN ADMINISTRATION ON BLOOD OXYGEN CONTENT AND OXYGEN SATURATION

\begin{tabular}{|c|c|c|c|c|c|c|c|}
\hline \multicolumn{3}{|c|}{ Oxygen Saturation ( $\%)$} & \multicolumn{5}{|c|}{ Oxygen Content (vol. \%) } \\
\hline $\begin{array}{l}\text { Before } \\
\text { Oxygen }\end{array}$ & Increase & $\begin{array}{l}\text { After } \\
\text { Oxygen }\end{array}$ & $\begin{array}{l}\text { Before } \\
\text { Oxygen }\end{array}$ & Increase & $\begin{array}{c}\text { After } \\
\text { Oxygen }\end{array}$ & & \\
\hline $\begin{array}{l}64 \cdot 5 \\
66 \cdot 0 \\
66 \cdot 4 \\
74 \cdot 0\end{array}$ & $\begin{array}{l}15 \cdot 5 \\
32 \cdot 5 \\
11 \cdot 8 \\
14 \cdot 2\end{array}$ & $\begin{array}{l}80 \cdot 0 \\
98 \cdot 3 \\
78 \cdot 2 \\
88 \cdot 2\end{array}$ & $\begin{array}{r}7 \cdot 7 \\
17 \cdot 8 \\
9 \cdot 1 \\
10 \cdot 1\end{array}$ & $\begin{array}{r}2 \cdot 4 \\
11 \cdot 2 \\
1 \cdot 6 \\
1 \cdot 9\end{array}$ & $\begin{array}{l}10 \cdot 1 \\
26 \cdot 6 \\
10 \cdot 7 \\
11 \cdot 9\end{array}$ & $\begin{array}{l}\text { Av. inc. } O_{2} \text { content } \\
\text { Av. inc. } \mathrm{O}_{2} \text { satn }\end{array}$ & $\begin{array}{l}=4 \cdot 3 \\
=18 \cdot 45\end{array}$ \\
\hline $\begin{array}{l}80 \cdot 0 \\
83 \cdot 4 \\
84 \cdot 0 \\
84 \cdot 0 \\
87 \cdot 3 \\
88 \cdot 3 \\
89 \cdot 5\end{array}$ & $\begin{array}{r}9.7 \\
12.9 \\
9.6 \\
13.4 \\
10.7 \\
11.7 \\
15.5\end{array}$ & $\begin{array}{r}89 \cdot 7 \\
96 \cdot 2 \\
93 \cdot 6 \\
97 \cdot 4 \\
96 \cdot 0 \\
100 \cdot 0 \\
105 \cdot 0\end{array}$ & $\begin{array}{l}14 \cdot 7 \\
22 \cdot 4 \\
15 \cdot 2 \\
18 \cdot 4 \\
24 \cdot 6 \\
11 \cdot 9 \\
27 \cdot 0\end{array}$ & $\begin{array}{l}1 \cdot 8 \\
3 \cdot 5 \\
1 \cdot 7 \\
2 \cdot 9 \\
2 \cdot 4 \\
1 \cdot 6 \\
4 \cdot 8\end{array}$ & $\begin{array}{l}16 \cdot 5 \\
25 \cdot 9 \\
16 \cdot 9 \\
21 \cdot 3 \\
27 \cdot 0 \\
13 \cdot 5 \\
31 \cdot 8\end{array}$ & $\begin{array}{l}\text { Av. inc. } O_{2} \text { content } \\
\text { Av. inc. } O_{2} \text { satn }\end{array}$ & $\begin{array}{r}=2 \cdot 7 \\
=11 \cdot 9\end{array}$ \\
\hline $\begin{array}{r}90 \cdot 1 \\
90 \cdot 5 \\
91 \cdot 0 \\
92 \cdot 0 \\
92 \cdot 2 \\
92 \cdot 4 \\
92 \cdot 6 \\
93 \cdot 0 \\
94 \cdot 4 \\
95 \cdot 3 \\
100 \cdot 0\end{array}$ & $\begin{array}{c}3 \cdot 2 \\
3 \cdot 7 \\
7 \cdot 0 \\
11 \cdot 0 \\
0 \\
7 \cdot 6 \\
11 \cdot 0 \\
8 \cdot 0 \\
0 \\
2 \cdot 9 \\
4 \cdot 0\end{array}$ & $\begin{array}{r}93 \cdot 3 \\
94 \cdot 2 \\
98 \cdot 0 \\
103 \cdot 0 \\
92 \cdot 2 \\
100 \cdot 0 \\
103 \cdot 6 \\
101 \cdot 0 \\
94 \cdot 4 \\
98 \cdot 2 \\
104 \cdot 0\end{array}$ & $\begin{array}{l}10 \cdot 9 \\
20 \cdot 1 \\
22 \cdot 4 \\
21 \cdot 5 \\
11 \cdot 5 \\
24 \cdot 2 \\
25 \cdot 6 \\
20 \cdot 0 \\
23 \cdot 3 \\
19 \cdot 9 \\
19 \cdot 8\end{array}$ & $\begin{array}{l}1 \cdot 5 \\
0 \cdot 6 \\
1 \cdot 8 \\
2 \cdot 5 \\
0 \\
1 \cdot 9 \\
3 \cdot 0 \\
1 \cdot 7 \\
0 \\
1 \cdot 6 \\
0 \cdot 8\end{array}$ & $\begin{array}{l}11 \cdot 4 \\
20 \cdot 7 \\
24 \cdot 2 \\
24 \cdot 0 \\
11 \cdot 5 \\
26 \cdot 1 \\
28 \cdot 6 \\
21 \cdot 7 \\
23 \cdot 3 \\
20 \cdot 5 \\
20 \cdot 6\end{array}$ & $\begin{array}{l}\text { Av. inc. } \mathrm{O}_{2} \text { content } \\
\text { Av. inc. } \mathrm{O}_{2} \text { satn }\end{array}$ & $\begin{array}{l}=1 \cdot 3 \\
=5 \cdot 3\end{array}$ \\
\hline
\end{tabular}

$89 \%$ oxygen there was a further rise to $102 \%$, Prec and Cassels (1952) exposed 14 full-term infants aged $3 \frac{1}{2}$ days to an atmosphere of $90 \%$ oxygen and found that the average blood oxygen saturation rose from $93.6 \%$ to $100 \%$. In the present series the average blood oxygen saturation was $88 \%$ with a range from $61.5 \%$ to $102 \%$. An increase in the oxygen content and saturation of the blood occurred in nearly all our cases when oxygen was administered. The rise was not so great as that obtained by other workers but we never gave a higher concentration than $60 \%$.

These findings support the view that the blood of the premature baby has at most times a lower oxygen saturation than the fullterm baby or adult and that this saturation can be increased by giving oxygen.

The progress of all our babies was quite satisfactory during the period that they were being studied with regard to weight gain, temperature and general behaviour. With the excep-

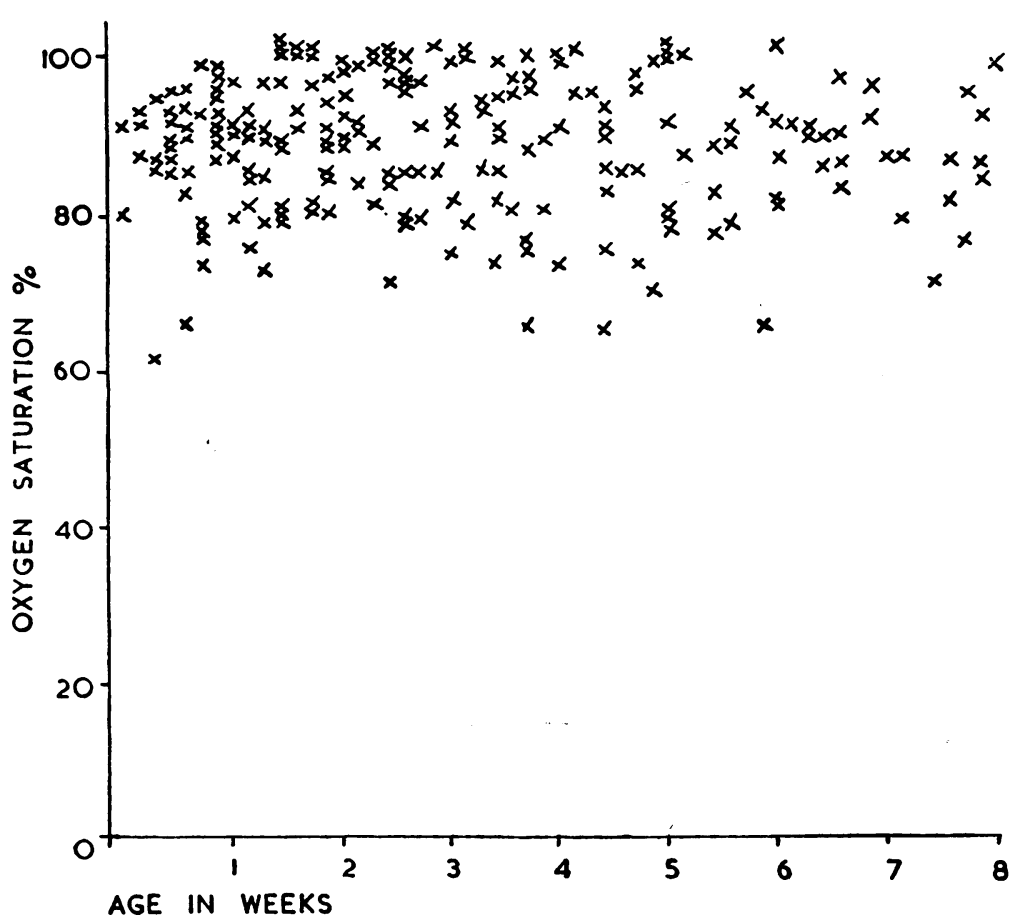

FIG. 3.-Percentage oxygen saturation tion of one infant who had a cyanotic congenital heart lesion, none showed cyanosis or any respiratory distress. Chest radiographs of three whose blood oxygen saturation fell below $70 \%$ on 

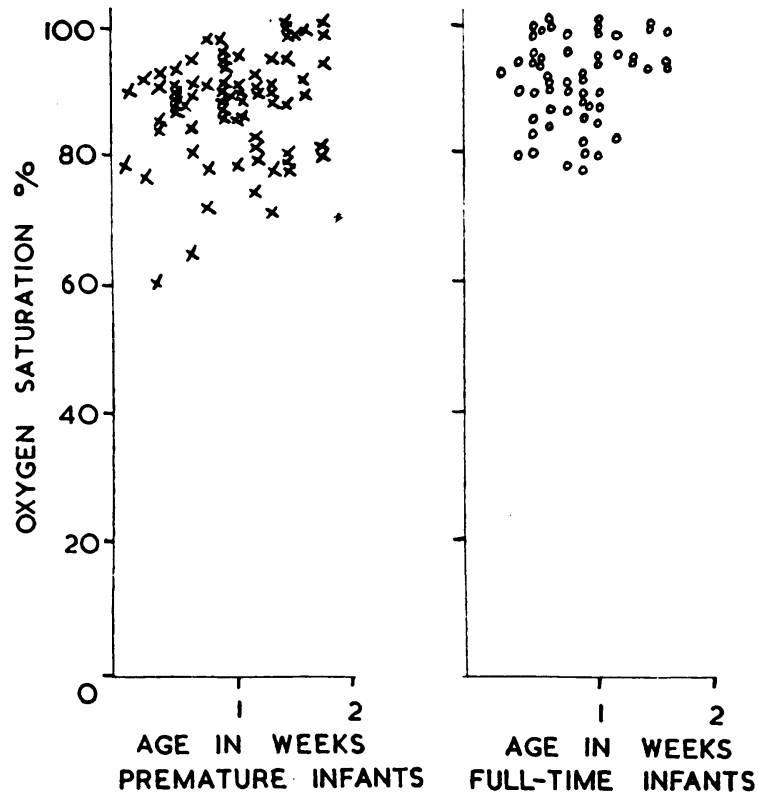

FIG. 4.-Percentage oxygen saturation of premature and full-term infants during the first two weeks of life.

three or more occasions revealed normal lung fields and a normal cardiac outline. It seemed to us that the progress of these babies is unlikely to have been improved by the prolonged administration of oxygen.

The high blood oxygen content, as opposed to the percentage saturation, that was found in the first few days of life when the haemoglobin was high, is worthy of note. In a number of cases it was over 25 vol. $\%$. With oxygen administration and a high haemoglobin it would not be difficult to reach figures over $30 \mathrm{vol} . \%$.

\section{Summary}

The blood oxygen saturations of 40 premature babies were determined on 238 occasions between birth and 3 months by a microgasometric method. The mean value was $88.8 \%$ in comparison with $93 \%$ for full-term infants. The administration of oxygen resulted in a rise in the blood oxygen content and saturation on 21 of the 23 times that it was given. There was, however, no indication that prolonged oxygen therapy was needed by any of the infants at the time they were being studied. It is unlikely that the routine study of blood oxygen levels of healthy premature babies would assist in their general management.

We are grateful to Dr. E. Sherwood Jones, now in the Department of Medicine, and to members of the Liverpool School of Tropical Medicine for their guidance when we were learning the technique of microgasometric analysis, and to Mr. J. Ireland for preparing the chemicals and giving assistance in the calibration of pipettes.

Dr. P. M. Russell held the Ridgway Fellowship in Paediatrics of the University of Liverpool while conducting this work which formed the basis for a thesis accepted by the University for the degree of M.D.

\section{REFERENCES}

Arthurton, M., O'Brien, D. and Mann, T. (1954). Archives of Disease in Childhood, 29, 38.

Graham, B. D., Reardon, H. S., Wilson, J. L. Tsao, M. U. and Baumann, M. L. (1950). Pediatrics, 6, 55

Hüfner, G. (1894). Arch. Anat. Physiol. (Lpz.), [Physiol. Abt.], p. 130. Hultgren, H. N. and Hackett, A. J. (1950). Pediatrics, 6, 93.

Jonxis, J. H. P. (1953). In Anoxia of the Newborn Infant: a Svmposium organized by the Council for International Organizations of Medical Sciences, p. 127. Oxford.

Lundsgaard, C and Möller, E. (1922), J exp. Med, 36, 559.

Malm, E. (1953). In Anoxia of the Newborn Infant, a Symposium, p. 195.

Merritt, K. K. and Davidson, L. T. (1934). Amer. J. Dis. Child., 47,261 .

Prec, K. J. and Cassels, D. E. (1952). Pediatrics, 9, 756.

Roughton, F. J. W. and Scholander, P. F. (1943). J. biol. Chem. 148, 541 .

Smith, C. A and Kaplan, E. (1942). Amer. J. Dis. Child, 64, 843.

Tavlor, E. S. (1954). Pediat. Clin. N. Amer., August, p. 587

Taylor, E. S. (1954). Pediat. Clin. N. Amer., August, p. 587. Child., 63, 1080. 